Check for updates

Cite this: RSC Adv., 2019, 9, 37061

Received 25th September 2019 Accepted 6th November 2019

DOI: 10.1039/c9ra07764b

rsc.li/rsc-advances

\section{Biofunctional few-layer metal dichalcogenides and related heterostructures produced by direct aqueous exfoliation using phospholipids $\uparrow$}

\author{
Aled T. Williams, ${ }^{a}$ Roberto Donno, (D) ${ }^{b}$ Nicola Tirellib and Robert A. W. Dryfe (D) *ac \\ We report a novel, inexpensive and green method for preparing aqueous dispersions of various \\ biofunctional transition-metal dichalcogenides $\left(\mathrm{MoS}_{2}, \mathrm{WS}_{2}, \mathrm{TiS}_{2}\right.$ and $\left.\mathrm{MoSe}_{2}\right)$ and their related \\ heterostructures directly via ultrasonic exfoliation mediated by the presence of phospholipids. The \\ dispersions predominantly consist of few-layer flakes coated with 1,2-dioleoyl-sn-glycero-3- \\ phosphocholine (DOPC), as confirmed by Raman, photoluminescence and X-ray photoelectron \\ spectroscopies. The phospholipid coating renders the flakes biofunctional, which coupled with the \\ unique properties of transition-metal dichalcogenides and their heterostructures, suggests this method \\ will have great potential in biological applications.
}

Transition-metal dichalcogenides (TMDCs) and other species of layered inorganic compounds are currently attracting much interest as the next generation of two-dimensional (2D) materials beyond graphene. ${ }^{1}$ These materials, notably $\mathrm{MoS}_{2}, \mathrm{WS}_{2}$ and hexagonal boron nitride (hBN), have already found applications in fields such as optoelectronics and energy storage due to their unique physical properties. ${ }^{2-6}$ Structurally, TMDCs are 2D layers of transition metal atoms, $\mathrm{M}$, each covalently bound to two chalcogen atoms, $\mathrm{X}$, and held together by van der Waals forces. The combination of metal and chalcogen influences the electronic properties of the material, for example $\mathrm{TiS}_{2}$ is a semimetal whilst $\mathrm{MoS}_{2}$ is a semiconductor in its naturally occurring, $2 \mathrm{H}$, phase. ${ }^{7}$ In addition to $\mathrm{MX}_{2}$ compounds, similar structures are also embodied by $\mathrm{hBN}, \mathrm{Bi}_{2} \mathrm{Te}_{3}$, transition-metal oxides, silicene, germanene and phosphorene (exfoliated black phosphorus) providing a range of new 2D materials for exploitation based on their individual attributes. ${ }^{1,8}$ There is also growing interest in hetero-structures formed from these materials, i.e. stacked combinations of different $2 \mathrm{D}$ species, offering further diversity in the properties that can be harvested from these layered materials., ${ }^{2,9-11}$

Solution processing of 2D materials is essential for industrial applications ${ }^{12}$ where the time-intensive and costly approaches of micromechanical cleavage and chemical vapour deposition

${ }^{a}$ School of Chemistry, University of Manchester, Oxford Road, Manchester, M13 9PL, UK. E-mail: robert.dryfe@manchester.ac.uk

${ }^{b}$ Laboratory of Polymers and Biomaterials, Fondazione Istituto Italiano di Tecnologia, Via Morego, 30, Genoa, Italy

${ }^{c}$ National Graphene Institute, University of Manchester, Oxford Road, Manchester, M13 9PL, UK

$\dagger$ Electronic supplementary information (ESI) available. See DOI: $10.1039 / \mathrm{c} 9 \mathrm{ra} 07764 \mathrm{~b}$ hinder the commercial viability of some technologies. Several liquid-phase exfoliation methods have been reported over recent years, the majority of which have been based on earlier methods applied to the exfoliation of graphite. ${ }^{13,14}$ Notably, direct sonication of bulk powders in high boiling-point (HBP) solvents such as $N$-methyl-2-pyrrolidone (NMP) has been shown to produce monolayer to few-layer (layer number, $n \leq 3$ ) dispersions of TMDCs and other layered inorganic materials with reasonable stabilities and concentrations (up to $40 \mathrm{mg}$ $\left.\mathrm{mL}^{-1}\right) .^{15,16}$ However, direct sonication using HBP solvents raises obvious economic, environmental and safety concerns and furthermore, HBP solvent residues in thin films fabricated from such dispersions can be difficult to remove, which can be detrimental to subsequent applications in electronics. ${ }^{17}$ Alternative preparation techniques, such as chemical and electrochemical Li-intercalation ${ }^{18-20}$ and various surface functionalization strategies using organic molecules, ${ }^{19,21}$ often involve multiple steps and undesirable reaction conditions.

Aqueous exfoliation methods can address many of these issues. However, successful liquid-phase exfoliation requires that the enthalpy of mixing per unit volume associated with the dispersal of the $2 \mathrm{D}$ flakes is close to zero, and it has been shown that for TMDCs ${ }^{22}$ optimal solvents are characterized by surface tensions in the region of $40 \mathrm{~mJ} \mathrm{~m}^{-2}$, with water falling outside this range at $72.75 \mathrm{~mJ} \mathrm{~m}^{-2}$ (at $20{ }^{\circ} \mathrm{C}$ )..$^{23}$ However, aqueous dispersions of hydrophobic flakes can be stabilized electrostatically or sterically, and a number of recent reports detail the use of surfactants or polymers in facilitating the aqueous exfoliation of layered inorganic materials via the application of ultrasonic energy. ${ }^{24-28}$ Herein, we report on a new exfoliation method, where phospholipids are used as electrostatic stabilizing agents in preparing aqueous dispersions of TMDCs 
directly via sonication of the bulk materials. Phospholipids have the additional advantage of imparting bio-compatibility to the $2 \mathrm{D}$ materials. We also demonstrate that the mixing and subsequent sonication of these dispersions result in the formation of hetero-structured materials, whose optoelectronic characteristics can be modified by the respective ratios of the parent materials.

Briefly, our method involves sonicating $\mathrm{MX}_{2}$ powders in ultra-pure water containing phospholipid for $12 \mathrm{~h}$, followed by a centrifugation to purify the dispersions from large aggregates (full details can be found in the ESI $\dagger$ ). We have previously described how this procedure can be applied to graphene exfoliation, ${ }^{29}$ where we have shown that the amount of $2 \mathrm{D}$ material dispersed was dependent on the phospholipid concentration and the fluidity of the phospholipid aliphatic chains. Herein, we report that the same method can be used to produce meta-stable aqueous dispersions for each TMDC tested, namely $\mathrm{MoS}_{2}, \mathrm{WS}_{2}, \mathrm{TiS}_{2}$ and $\mathrm{MoSe}_{2}$, as well as hBN. For the dispersions characterised in this study, $\mathrm{MX}_{2}$ and $\mathrm{hBN}$ powders were sonicated in ultra-pure water with 1,2-dioleoyl-snglycero-3-phosphocholine (DOPC) at a concentration of $0.2 \mathrm{mg}$ $\mathrm{mL}^{-1}$, resulting in dispersed concentrations in the range of 0.01-0.1 $\mathrm{mg} \mathrm{mL}^{-1}$, depending on the 2D material used. DOPC was selected as the lipid of choice on the basis of our graphene dispersion work, ${ }^{29}$ as the fluidity of this phospholipid chain was shown to impart a good level of dispersion stability compared to other phospholipids. Thermogravimetric analysis (TGA) performed on freeze-dried dispersions of $\mathrm{MoS}_{2}, \mathrm{WS}_{2}$ and $\mathrm{TiS}_{2}$ suggest that the method typically produces fresh dispersions containing $10-20 \%$ weight of dispersed 2D-material (refer to Fig. S1 in the ESI $\dagger$ ), comparable to that observed for graphene dispersions produced by the same method. ${ }^{29}$

Ultraviolet-visible (UV-vis) spectroscopy confirmed the presence of dispersed few-layer $\mathrm{MX}_{2}$ species, with the following characteristic major absorption peaks: 393, 450, 608 and $665 \mathrm{~nm}$ for $\mathrm{MoS}_{2} ;^{3,30,31}$ 412, 697 and $805 \mathrm{~nm}$ for $\mathrm{MoSe}_{2}{ }^{3,32}$ $593 \mathrm{~nm}$ for $\mathrm{TiS}_{2}{ }^{33}$ and $624 \mathrm{~nm}$ for $\mathrm{WS}_{2} \cdot{ }^{3,30}$ No absorption peaks could be discerned from the Rayleigh scattering in the spectrum for hBN. The spectra are presented in Fig. 1A together with photographs of the dispersions.

Hydrodynamic diameter values obtained via dynamic light scattering (DLS) measurements are presented in Table 1, providing rough estimates (between tens and hundreds of $\mathrm{nm}$, due to the approximations in the technique) of colloid size which were found to be comparable to those observed for graphene dispersions produced by the same method. ${ }^{29}$ The dispersed TMDCs were characterized by negative $\zeta$ potential values at neutral $\mathrm{pH}$ (see Table 1), although smaller in magnitude to those observed for the graphene dispersions $(-34 \mathrm{mV})$. Shorter-term stability is expected as a result of this observation and this is confirmed by comparison of the time-dependent reductions in optical density presented in Table 1 . It is worth noting that the $\mathrm{TiS}_{2}$ dispersions, approximately $12 \mathrm{~h}$ after preparation, produce a strong sulphurous odour: it is known that this material is prone to oxidation in aqueous solution, most likely via the following reaction: ${ }^{34}$
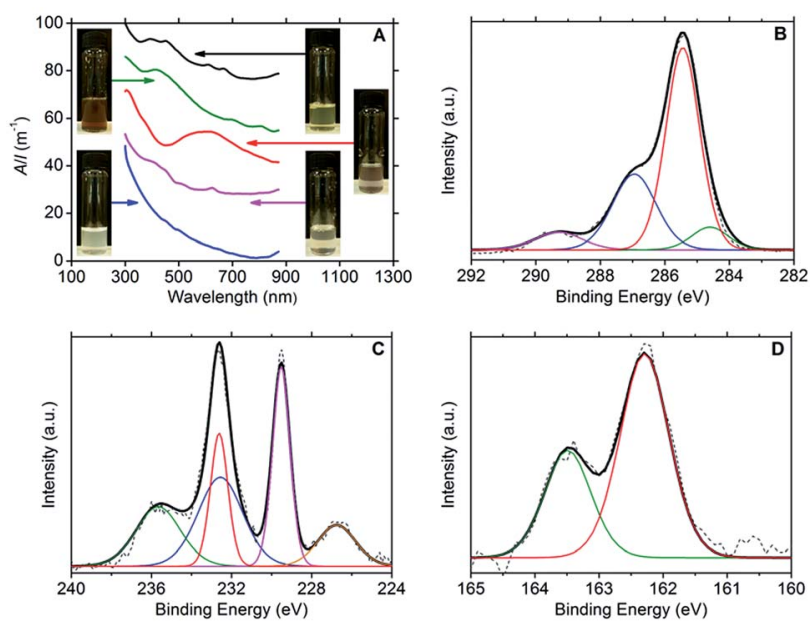

Fig. 1 (A) UV-vis absorbance spectra of the aqueous DOPC/2Dmaterial dispersions (from top to bottom): $\mathrm{MoS}_{2}$ (black line), $\mathrm{MoSe}_{2}$ (green line), $\mathrm{TiS}_{2}$ (red line), $\mathrm{WS}_{2}$ (purple line) and hBN (blue line). The stacked spectra are in proportion to each other. (B) C1s XPS spectrum of a DOPC/MoS 2 dispersion drop cast onto $\mathrm{Si} / \mathrm{SiO}_{2}$ substrate. In the fitting, the green line corresponds to the $\mathrm{C}-\mathrm{C} \mathrm{sp}^{2}$ peak, the red line to the $\mathrm{C}-\mathrm{C} \mathrm{sp}^{3}$ peak, the blue line to the $\mathrm{C}-\mathrm{O} / \mathrm{C}-\mathrm{N}$ peak and the purple line to the $\mathrm{O}-\mathrm{C}=\mathrm{O}$ peak. (C) Mo3d XPS spectrum of a DOPC/MoS 2 dispersion drop cast onto $\mathrm{Si} / \mathrm{SiO}_{2}$ substrate. In the fitting, the orange line corresponds to the $S 2 \mathrm{~s}$ peak, the purple line to the $\mathrm{MO}^{4+} 3 \mathrm{~d}_{5 / 2}$ peak, the red line to the $\mathrm{Mo}^{4+} 3 d_{3 / 2}$ peak, the blue line to the $\mathrm{Mo}^{6+} 3 d_{5 / 2}$ peak and the green line to the $M^{6+} 3 d_{3 / 2}$ peak. (D) S2p XPS spectrum of a DOPC/MoS 2 dispersion drop cast onto $\mathrm{Si} / \mathrm{SiO}_{2}$ substrate. The fitting is for the $S 2 p$ doublet, with the red line depicting the $S 2 p_{3 / 2}$ peak and the green line the $S 2 p_{1 / 2}$ peak.

$$
\mathrm{TiS}_{2}+x \mathrm{H}_{2} \mathrm{O} \rightarrow \mathrm{TiS}_{2-x} \mathrm{O}_{x}+x \mathrm{H}_{2} \mathrm{~S}
$$

As the hBN dispersions were found to precipitate at a significantly faster rate to the other $2 \mathrm{D}$ materials, no further characterisation work was conducted on hBN dispersions as part of this study.

$\mathrm{X}$-ray photoelectron spectroscopy (XPS) was used to confirm the presence of DOPC and $\mathrm{MX}_{2}$ in the dispersions; refer to Fig. 1B-D (and Fig. S2-S4 in the ESI $\dagger$ ). For DOPC, the C1s spectrum for all samples (dispersions of $\mathrm{MoS}_{2}, \mathrm{MoSe}_{2}, \mathrm{WS}_{2}$ and $\mathrm{TiS}_{2}$ ) showed peaks representatives of DOPC at average binding energies of $284.5 \mathrm{eV}\left(\mathrm{C}-\mathrm{C} \mathrm{sp}{ }^{2}\right), 285.3 \mathrm{eV}\left(\mathrm{C}-\mathrm{C} \mathrm{sp}{ }^{3}\right), 286.9 \mathrm{eV}$ (combined signal for $\mathrm{C}-\mathrm{O}$ and $\mathrm{C}-\mathrm{N})$ and $289.2 \mathrm{eV}(\mathrm{O}-\mathrm{C}=\mathrm{O}) \cdot{ }^{29}$ Furthermore, the phosphorous and nitrogen peaks were found to be present at similar percentage atomic concentrations appearing at average binding energies of $134.0 \mathrm{eV}$ and $134.9 \mathrm{eV}$ $\left(\mathrm{P} 2 \mathrm{p}_{3 / 2}\right.$ and $\left.\mathrm{P} 2 \mathrm{p}_{1 / 2}\right)$ and $402.9 \mathrm{eV}$ respectively (N1s). For $\mathrm{MoS}_{2}$, the Mo3 $\mathrm{d}_{3 / 2}$ and Mo3d $\mathrm{d}_{5 / 2}$ doublet peaks were located at $232.6 \mathrm{eV}$ and $229.5 \mathrm{eV}$ respectively, with the S2s peak at $226.7 \mathrm{eV}$ and the $\mathrm{S} 2 \mathrm{p}$ doublet at $163.5 \mathrm{eV}$ and $162.3 \mathrm{eV}\left(\mathrm{S} 2 \mathrm{p}_{1 / 2}\right.$ and $\left.\mathrm{S} 2 \mathrm{p}_{3 / 2}\right)$. These binding energies are indicative of the expected $\mathrm{Mo}^{4+}$ and $\mathrm{S}^{2-}$ chemical states. ${ }^{35-38}$ However, the presence of a peak at $235.6 \mathrm{eV}$ is indicative of the $\mathrm{Mo}_{3 / 2}$ doublet peak for $\mathrm{Mo}^{6+}$, and fitting reveals the complementary $\mathrm{Mo}_{5 / 2}$ peak at $232.5 \mathrm{eV}$, which strongly suggests that $\mathrm{MoO}_{3}$ is present at approximately the same concentration as $\mathrm{MoS}_{2}$ (percentage atomic concentrations 
Table 1 Summary of $\zeta$ potential and DLS hydrodynamic diameter values $(D)$ as measured for various 2D-material/DOPC aqueous dispersions, as well as stability data in the form of reduction in optical density versus day 0 (ODR)

\begin{tabular}{|c|c|c|c|c|c|c|}
\hline Material & $\zeta(\mathrm{mV})$ & $D(\mathrm{~nm})$ & ODR day $10^{a}$ & ODR day $20^{a}$ & ODR day $30^{a}$ & ODR day $50^{a}$ \\
\hline $\mathrm{MoS}_{2}$ & -20 & 142 & $8 \%$ & $16 \%$ & $32 \%$ & $71 \%$ \\
\hline $\mathrm{MoSe}_{2}$ & -28 & 164 & $14 \%$ & $23 \%$ & $34 \%$ & $87 \%$ \\
\hline $\mathrm{WS}_{2}$ & -15 & 255 & $14 \%$ & $29 \%$ & $51 \%$ & $85 \%$ \\
\hline hBN & -23 & 295 & $70 \%$ & $74 \%$ & $80 \%$ & $85 \%$ \\
\hline Graphene & -34 & 190 & - & $11 \%^{b}$ & $25 \%^{b}$ & $43 \%^{b}$ \\
\hline
\end{tabular}

${ }^{a}$ Optical density measured at $A_{608}\left(\mathrm{MoS}_{2}\right), A_{805}\left(\mathrm{MoSe}_{2}\right), A_{565}\left(\mathrm{TiS}_{2}\right), A_{624}\left(\mathrm{WS}_{2}\right), A_{300}(\mathrm{hBN})$ and $A_{660}$ (graphene), where subscripts are wavelengths in nanometres. Graphene data at $A_{660}$ taken from ref. $29 .{ }^{b}$ Optical density data for graphene measured at $A_{660}$ at time points: 22,41 and 56 days.

of $47 \% \mathrm{Mo}^{4+}$ and $\left.53 \% \mathrm{Mo}^{6+}\right) \cdot{ }^{37-40}$ The $\mathrm{Mo}^{6+}$ state was more heavily detected for the $\mathrm{MoSe}_{2}$ dispersions (percentage atomic concentrations of $11 \% \mathrm{Mo}^{4+}$ and $89 \% \mathrm{Mo}^{6+}$ ). The $\mathrm{Mo3d}_{3 / 2}$ and Mo3d $_{5 / 2}$ doublet peaks for $\mathrm{Mo}^{6+}$ appear at $236.1 \mathrm{eV}$ and $232.9 \mathrm{eV}$ respectively, the same doublet peaks for $\mathrm{Mo}^{4+}$ being found at lower intensities at $232.5 \mathrm{eV}$ and $229.4 \mathrm{eV}$, with the $\mathrm{Se} 3 \mathrm{~d}_{3 / 2}$ and Se $3 \mathrm{~d}_{5 / 2}$ doublet peaks appearing at $56.6 \mathrm{eV}$ and $55.8 \mathrm{eV} \cdot{ }^{36}$ For $\mathrm{WS}_{2}$, two chemical states were also detected for tungsten, $\mathrm{W}^{4+}$ and $\mathrm{W}^{6+}$. The $\mathrm{W}_{4 \mathrm{f}_{5 / 2}}$ and $\mathrm{W} 4 \mathrm{f}_{7 / 2}$ doublet peaks expected for $\mathrm{WS}_{2}$ are observed at $34.6 \mathrm{eV}$ and $32.7 \mathrm{eV}$ with the $\mathrm{S} 2 \mathrm{p}$ doublet peaks appearing at $163.4 \mathrm{eV}$ and $162.2 \mathrm{eV}\left(\mathrm{S} 2 \mathrm{p}_{1 / 2}\right.$ and $\left.\mathrm{S} 2 \mathrm{p}_{3 / 2}\right)$. The $\mathrm{W}_{4} \mathrm{f}_{5 / 2}$ and $\mathrm{W}_{4} \mathrm{f}_{7 / 2}$ doublet peaks characteristic of the $\mathrm{W}^{6+}$ chemical state are seen at $38.1 \mathrm{eV}$ and $36.0 \mathrm{eV}$, and represent the dominant binding energies of the W4f signal (percentage atomic concentrations of $12 \% \mathrm{~W}^{4+}$ and $\left.88 \% \mathrm{~W}^{6+}\right),{ }^{35,36,41}$ which coupled with the weak S2p signal suggests that the samples contained significant amounts of $\mathrm{WO}_{3}$. For TiS 2 , the Ti2 $\mathrm{p}_{1 / 2}$ and Ti2 $\mathrm{p}_{3 / 2}$ doublet peaks appear at $464.8 \mathrm{eV}$ and $459.1 \mathrm{eV}$ respectively, with the S2p doublet peaks appearing at $165.2 \mathrm{eV}$ and $163.9 \mathrm{eV}\left(\mathrm{S} 2 \mathrm{p}_{1 / 2}\right.$ and $\left.\mathrm{S} 2 \mathrm{p}_{3 / 2}\right)$. These binding energies are indicative of the expected $\mathrm{Ti}^{4+}$ and $\mathrm{S}^{2-}$ chemical states. ${ }^{42,43}$ However, as with that observed for the $\mathrm{WS}_{2}$ sample, a weak S2p signal intensity was observed when compared to the Ti2p signal intensity. This observation, in conjunction with the dispersion stability data, suggests that oxidised titanium is also present in significant quantity. The partial oxidation of the TMDCs, detected by the XPS, could explain the lower long-term stability of the DOPC-stabilised dispersions relative to the graphene sample (see Table 1). Consistent with this, it is noted that the $\mathrm{TiS}_{2}$ sample has the lowest level of dispersion stability.

Raman spectroscopy was used to further characterise the DOPC/MX $\mathrm{MX}_{2}$ dispersions and to confirm the presence of few-layer flakes. Analysis was performed on drop-cast samples using $\mathrm{Si}$ / $\mathrm{SiO}_{2}$ substrates. For $\mathrm{MoS}_{2}$, spectra diagnostic of few-layer flakes predominated with the $\mathrm{A}_{1 \mathrm{~g}}$ and $\mathrm{E}_{2 \mathrm{~g}}^{1}$ typically appearing at $406 \mathrm{~cm}^{-1}$ and $382 \mathrm{~cm}^{-1}$ respectively, separated by $24 \mathrm{~cm}^{-1}$, yielding maximum photoluminescent (PL) emission at $675 \mathrm{~nm}$ $(1.84 \mathrm{eV})$, which is consistent with literature values for few-layer $\mathrm{MoS}_{2} \cdot{ }^{\mathbf{4 4 - 4 9}}$ Similarly, the spectra measured for the $\mathrm{WS}_{2}$ samples were found to be representative of few-layer material, ${ }^{\mathbf{4 7}-52}$ with $\mathrm{A}_{1 \mathrm{~g}}$ and $\mathrm{E}_{2 \mathrm{~g}}^{1}$ appearing at $419 \mathrm{~cm}^{-1}$ and $351 \mathrm{~cm}^{-1}$ respectively, separated by $68 \mathrm{~cm}^{-1}$ and yielding maximum photoluminescent (PL) emission at $633 \mathrm{~nm}(1.96 \mathrm{eV})$. Few-layer flakes were also detected for $\mathrm{MoSe}_{2}$ and $\mathrm{TiS}_{2}$. For $\mathrm{MoSe}_{2}$, this was confirmed by the following representative peaks: $351 \mathrm{~cm}^{-1}$ $\left(\mathrm{B}_{2 \mathrm{~g}}^{1}\right), 285 \mathrm{~cm}^{-1}\left(\mathrm{E}_{2 \mathrm{~g}}^{1}\right)$ and $241 \mathrm{~cm}^{-1}\left(\mathrm{~A}_{1 \mathrm{~g}}\right)^{48,49,53}$ and for $\mathrm{TiS}_{2}$ : $377 \mathrm{~cm}^{-1}\left(\mathrm{~A}_{2 \mathrm{u}}\right), 333 \mathrm{~cm}^{-1}\left(\mathrm{~A}_{1 \mathrm{~g}}\right)$ and $233 \mathrm{~cm}^{-1}\left(\mathrm{E}_{\mathrm{g}}\right),{ }^{33,49,54}$ with the $A_{1 g}: A_{2 u}$ peak intensity ratio at approximately 2.0 (compare to a value of 1.6 measured for the bulk powder starting-material). ${ }^{33}$ Weaker PL emissions were observed for the samples derived from the $\mathrm{MoSe}_{2}$ and $\mathrm{TiS}_{2}$ dispersions, as compared to those
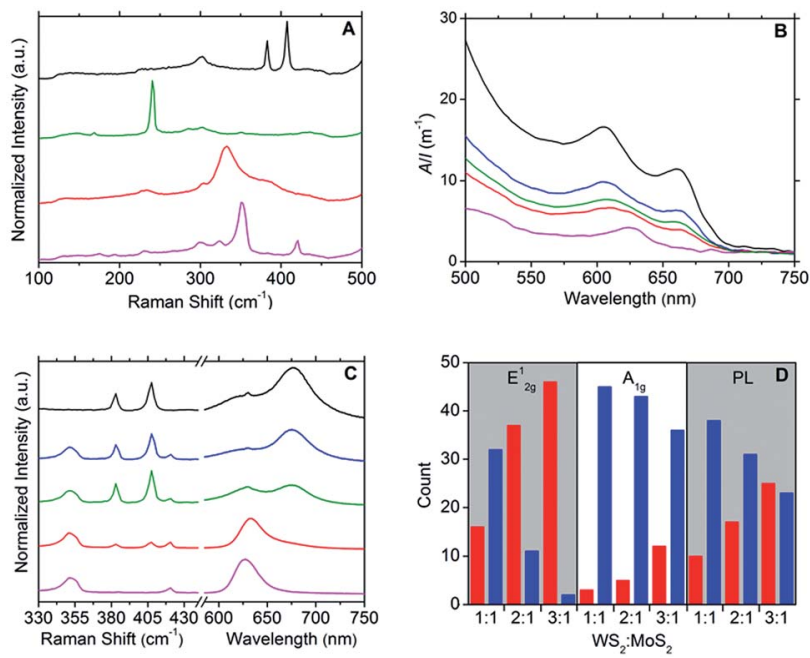

Fig. 2 (A) Raman spectra (532 nm excitation) of the DOPC/MX dispersions drop cast onto $\mathrm{Si} / \mathrm{SiO}_{2}$ substrates, corresponding (from top to bottom) to $\mathrm{MoS}_{2}$ (black line), $\mathrm{MoSe}_{2}$ (green line), $\mathrm{TiS}_{2}$ (red line) and $\mathrm{WS}_{2}$ (purple line). (B) UV-vis spectra of the following aqueous DOPC/ 2D-material dispersions (from top to bottom): $\operatorname{MoS}_{2}$ (black line), $1: 1$ $\mathrm{WS}_{2}: \mathrm{MoS}_{2}$ heterostructures (blue line), 2:1 WS $2: \mathrm{MoS}_{2}$ heterostructures (green line), $3: 1 \mathrm{WS}_{2}: \mathrm{MoS}_{2}$ heterostructures (red line) and $W_{2}$ (purple line). (C) Typical Raman and PL spectra (532 nm excitation) measured for the following DOPC/2D-material dispersions drop cast onto $\mathrm{Si} / \mathrm{SiO}_{2}$ substrates (from top to bottom): $\mathrm{MoS}_{2}$ (black line), $1: 1$ $\mathrm{WS}_{2}: \mathrm{MoS}_{2}$ heterostructures (blue line), $2: 1 \mathrm{WS}_{2}: \mathrm{MoS}_{2}$ heterostructures (green line), $3: 1 \mathrm{WS}_{2}: \mathrm{MoS}_{2}$ heterostructures (red line) and $W_{2}$ (purple line). (D) Histograms showing the relative proportions of dominant peak intensities in the Raman $\left(E_{2 g}^{1}\right.$ and $\left.A_{1 g}\right)$ and PL spectra $\left(\lambda_{\max }\right)$ of aqueous DOPC-mediated dispersions of $1: 1,2: 1$ and $3: 1$ $\mathrm{WS}_{2}: \mathrm{MoS}_{2}$ heterostructures. Instances where the peak intensities arising from $\mathrm{WS}_{2}$ are greater than those from $\mathrm{MoS}_{2}$ are binned on the left-hand side (red columns) with the converse case binned on the right-hand side (blue columns); a bin size of 48 measurements (at different sample spots) was used in all instances. 
from $\mathrm{MoS}_{2}$ and $\mathrm{WS}_{2}$ dispersions. Fig. 2A and S5-S8 in the ESI $\dagger$ give typical examples of the Raman and PL spectra measured.

Finally, atomic force microscopy (AFM) performed on dropcast samples of $\mathrm{DOPC} / \mathrm{MoS}_{2}$ dispersions (clean mica substrates were used) showed structures similar to those observed for graphene dispersions produced by the same method, ${ }^{29}$ with an average height of $40 \mathrm{~nm}$. The AFM height images showed objects characterized by "steps" with a height of $5 \mathrm{~nm}$ (or multiple of $5 \mathrm{~nm}$ ), which is a thickness comparable to that of a DOPC bilayer; ${ }^{55-58}$ refer to Fig. S9 in the ESI $\uparrow$ for further details.

Supplemental to the novel properties offered by true 2D materials and their few-layer counterparts, mixed van der Waals stacking of different 2D materials to form heterostructures, endow few-layer materials with scope to impart bespoke properties. $^{2,9-11,38,59}$ In addition to our method detailed above for the production of aqueous DOPC/MX $\mathrm{MX}_{2}$ dispersions, we also present a fast and single-step method to prepare aqueous DOPC/ heterostructure dispersions. Briefly, the method involves mixing the desired parent $\mathrm{DOPC} / \mathrm{MX}_{2}$ dispersions at specific volume ratios, after which the mixtures are sonicated for 10 minutes to facilitate the de-stacking and subsequent re-stacking of the parent layers into hetero-layered stacks. The method was used to prepare aqueous DOPC/WS $2: \mathrm{MoS}_{2}$ dispersions, where the resulting optoelectronic properties were found to be tuneable to the relative quantities of the parent dispersions used. UV-vis spectroscopy (Fig. 2B) was used as a simple screening tool for the selection of appropriate volume ratios of DOPC/WS $(x)$ and $\mathrm{DOPC} \mathrm{MoS}_{2}(y)$ dispersions to produce heterostructure dispersions with desired optoelectronic properties. For example, the UV-vis spectrum of the DOPC/WS $2: \mathrm{MoS}_{2}$ dispersion prepared using the $x: y$ ratio at $2: 1$ was found to be intermediate in character between those of the parent dispersions, with flakes (deposited on $\mathrm{Si} / \mathrm{SiO}_{2}$ substrates) also displaying intermediate character with regard to Raman and PL response; refer to Fig. 2C. Further illustration of this optoelectronic tuning is shown via the histograms presented in Fig. 2D, which are based on Raman and PL data measured from a total of 48 flakes per DOPC/WS $: \mathrm{MoS}_{2}$ dispersion $(x: y$ ratio at $1: 1$, $2: 1$ and $3: 1)$. The measured flakes were categorised into two conditions: one where the Raman $\left(\mathrm{A}_{1 \mathrm{~g}}\right.$ and $\left.\mathrm{E}_{2 \mathrm{~g}}^{1}\right)$ and PL $\left(\lambda_{\max }\right)$ intensities were greater for peaks emanating from $\mathrm{WS}_{2}$ (approximately $419 \mathrm{~cm}^{-1}$ for $\mathrm{A}_{1 \mathrm{~g}}, 350 \mathrm{~cm}^{-1}$ for $\mathrm{E}_{2 \mathrm{~g}}^{1}$ and $633 \mathrm{~nm}$ for $\mathrm{PL}$ ) and the other where the intensities were greater for peaks emanating from $\mathrm{MoS}_{2}$ (approximately $407 \mathrm{~cm}^{-1}$ for $\mathrm{A}_{1 \mathrm{~g}}$, $383 \mathrm{~cm}^{-1}$ for $E_{2 g}^{1}$ and $675 \mathrm{~nm}$ for PL). As expected, the intensities of the peaks arising from $\mathrm{WS}_{2}$ become greater as $x$ increases and as such, the findings show that manipulation of the $x: y$ volume ratio allows for the tuning of the predominant optoelectronic properties of heterostructure flakes.

\section{Conclusions}

In summary, a simple method has been presented to produce aqueous dispersions of phospholipid-coated few-layer transition-metal dichalcogenides $\left(\mathrm{MoS}_{2}, \mathrm{WS}_{2}, \mathrm{TiS}_{2}\right.$ and $\left.\mathrm{MoSe}_{2}\right)$ via single-step exfoliation of the bulk starting materials in water. Furthermore, the resulting dispersions can be subsequently mixed at pre-defined volume ratios to produce heterostructured dispersions thereby allowing for the tuning of the optoelectronic properties. The phospholipid coating renders the flakes biofunctional, which coupled with the unique properties of transition-metal dichalcogenides, indicates the great potential of this method for use in biological applications, for example in vivo sensing or drug transport.

\section{Conflicts of interest}

The authors declare no conflict of interest.

\section{Acknowledgements}

We thank Dr Andrew Thomas for XPS measurements. The authors gratefully acknowledge the Faculty of Medical and Human Sciences of The University of Manchester, and the EPSRC Programme Grant "2DHealth" (grant reference EP/ P00119X/1) for funding, and the Bio-AFM facility for technical support.

\section{Notes and references}

1 S. Z. Butler, S. M. Hollen, L. Y. Cao, Y. Cui, J. A. Gupta, H. R. Gutierrez, T. F. Heinz, S. S. Hong, J. X. Huang, A. F. Ismach, E. Johnston-Halperin, M. Kuno, V. V. Plashnitsa, R. D. Robinson, R. S. Ruoff, S. Salahuddin, J. Shan, L. Shi, M. G. Spencer, M. Terrones, W. Windl and J. E. Goldberger, ACS Nano, 2013, 7, 28982926.

2 X. P. Hong, J. Kim, S. F. Shi, Y. Zhang, C. H. Jin, Y. H. Sun, S. Tongay, J. Q. Wu, Y. F. Zhang and F. Wang, Nat. Nanotechnol., 2014, 9, 682-686.

3 Q. H. Wang, K. Kalantar-Zadeh, A. Kis, J. N. Coleman and M. S. Strano, Nat. Nanotechnol., 2012, 7, 699-712.

4 M. L. Tsai, S. H. Su, J. K. Chang, D. S. Tsai, C. H. Chen, C. I. Wu, L. J. Li, L. J. Chen and J. H. He, ACS Nano, 2014, 8, 8317-8322.

5 E. G. D. Firmiano, A. C. Rabelo, C. J. Dalmaschio, A. N. Pinheiro, E. C. Pereira, W. H. Schreiner and E. R. Leite, Adv. Energy Mater., 2014, 4, 1301380.

6 G. H. Lee, Y. J. Yu, X. Cui, N. Petrone, C. H. Lee, M. S. Choi, D. Y. Lee, C. Lee, W. J. Yoo, K. Watanabe, T. Taniguchi, C. Nuckolls, P. Kim and J. Hone, ACS Nano, 2013, 7, 79317936.

7 M. Chhowalla, H. S. Shin, G. Eda, L. J. Li, K. P. Loh and H. Zhang, Nat. Chem., 2013, 5, 263-275.

8 R. Mas-Balleste, C. Gomez-Navarro, J. Gomez-Herrero and F. Zamora, Nanoscale, 2011, 3, 20-30.

9 C. M. Huang, S. F. Wu, A. M. Sanchez, J. J. P. Peters, R. Beanland, J. S. Ross, P. Rivera, W. Yao, D. H. Cobden and X. D. Xu, Nat. Mater., 2014, 13, 1096-1101.

10 H. Fang, C. Battaglia, C. Carraro, S. Nemsak, B. Ozdol, J. S. Kang, H. A. Bechtel, S. B. Desai, F. Kronast, A. A. Unal, G. Conti, C. Conlon, G. K. Palsson, M. C. Martin, A. M. Minor, C. S. Fadley, E. Yablonovitch, R. Maboudian 
and A. Javey, Proc. Natl. Acad. Sci. U. S. A., 2014, 111, 61986202.

11 H. Wang, F. C. Liu, W. Fu, Z. Y. Fang, W. Zhou and Z. Liu, Nanoscale, 2014, 6, 12250-12272.

12 D. J. Finn, M. Lotya, G. Cunningham, R. J. Smith, D. McCloskey, J. F. Donegan and J. N. Coleman, J. Mater. Chem. C, 2014, 2, 925-932.

13 Y. Hernandez, V. Nicolosi, M. Lotya, F. M. Blighe, Z. Y. Sun, S. De, I. T. McGovern, B. Holland, M. Byrne, Y. K. Gun'ko, J. J. Boland, P. Niraj, G. Duesberg, S. Krishnamurthy, R. Goodhue, J. Hutchison, V. Scardaci, A. C. Ferrari and J. N. Coleman, Nat. Nanotechnol., 2008, 3, 563-568.

14 U. Khan, A. O'Neill, M. Lotya, S. De and J. N. Coleman, Small, 2010, 6, 864-871.

15 J. N. Coleman, M. Lotya, A. O'Neill, S. D. Bergin, P. J. King, U. Khan, K. Young, A. Gaucher, S. De, R. J. Smith, I. V. Shvets, S. K. Arora, G. Stanton, H. Y. Kim, K. Lee, G. T. Kim, G. S. Duesberg, T. Hallam, J. J. Boland, J. J. Wang, J. F. Donegan, J. C. Grunlan, G. Moriarty, A. Shmeliov, R. J. Nicholls, J. M. Perkins, E. M. Grieveson, K. Theuwissen, D. W. McComb, P. D. Nellist and V. Nicolosi, Science, 2011, 331, 568-571.

16 A. O'Neill, U. Khan and J. N. Coleman, Chem. Mater., 2012, 24, 2414-2421.

17 T. C. Hernandez, A. C. F. Blanco, A. T. Williams, M. Velicky, H. V. Patten, A. Colina and R. A. W. Dryfe, Electroanalysis, 2015, 27, 1026-1034.

18 J. Zheng, H. Zhang, S. H. Dong, Y. P. Liu, C. T. Nai, H. S. Shin, H. Y. Jeong, B. Liu and K. P. Loh, Nat. Commun., 2014, 5, 2995.

19 X. Huang, Z. Y. Zeng and H. Zhang, Chem. Soc. Rev., 2013, 42, 1934-1946.

20 R. A. Gordon, D. Yang, E. D. Crozier, D. T. Jiang and R. F. Frindt, Phys. Rev. B, 2002, 65, 125407.

21 L. Zhou, B. Z. He, Y. Yang and Y. G. He, RSC Adv., 2014, 4, 32570-32578.

22 G. Cunningham, M. Lotya, C. S. Cucinotta, S. Sanvito, S. D. Bergin, R. Menzel, M. S. P. Shaffer and J. N. Coleman, ACS Nano, 2012, 6, 3468-3480.

23 N. B. Vargaftik, B. N. Volkov and L. D. Voljak, J. Phys. Chem. Ref. Data, 1983, 12, 817-820.

24 R. J. Smith, P. J. King, M. Lotya, C. Wirtz, U. Khan, S. De, A. O'Neill, G. S. Duesberg, J. C. Grunlan, G. Moriarty, J. Chen, J. Z. Wang, A. I. Minett, V. Nicolosi and J. N. Coleman, Adv. Mater., 2011, 23, 3944-3948.

25 Y. G. Yao, L. Tolentino, Z. Z. Yang, X. J. Song, W. Zhang, Y. S. Chen and C. P. Wong, Adv. Funct. Mater., 2013, 23, 3577-3583.

26 M. D. J. Quinn, N. H. Ho and S. M. Notley, ACS Appl. Mater. Interfaces, 2013, 5, 12751-12756.

27 L. Guardia, J. I. Paredes, R. Rozada, S. Villar-Rodil, A. Martinez-Alonso and J. M. D. Tascon, RSC Adv., 2014, 4, 14115-14127.

28 A. Gupta, V. Arunachalam and S. Vasudevan, J. Phys. Chem. Lett., 2015, 6, 739-744.

29 A. T. Williams, R. Donno, N. Tirelli and R. A. W. Dryfe, $R S C$ Adv., 2018, 8, 19220-19225.
30 T. P. Nguyen, W. Sohn, J. H. Oh, H. W. Jang and S. Y. Kim, J. Phys. Chem. C, 2016, 120, 10078-10085.

31 I. Bilgin, F. Liu, A. Vargas, A. Winchester, M. K. L. Man, M. Upmanyu, K. M. Dani, G. Gupta, S. Talapatra, A. D. Mohite and S. Kar, ACS Nano, 2015, 9, 8822-8832.

32 N. Berahim, I. S. Amiri, T. Anwar, S. R. Azzuhri, M. N. S. Mohd Nasir, R. Zakaria, W. Y. Chong, C. K. Lai, S. H. Lee, H. Ahmad, M. A. Ismail and P. Yupapin, Results Phys., 2019, 12, 7-11.

33 P. C. Sherrell, K. Sharda, C. Grotta, J. Ranalli, M. S. Sokolikova, F. M. Pesci, P. Palczynski, V. L. Bemmer and C. Mattevi, ACS Omega, 2018, 3, 8655-8662.

34 E. Long, S. O'Brien, E. A. Lewis, E. Prestat, C. Downing, C. S. Cucinotta, S. Sanvito, S. J. Haigh and V. Nicolosi, npj 2D Mater. Appl., 2017, 1, 22.

35 M.-H. Chiu, C. Zhang, H.-W. Shiu, C.-P. Chuu, C.-H. Chen, C.-Y. S. Chang, C.-H. Chen, M.-Y. Chou, C.-K. Shih and L.-J. Li, Nat. Commun., 2015, 6, 7666.

36 J. Guo, Y. Shi, X. Bai, X. Wang and T. Ma, J. Mater. Chem. A, 2015, 3, 24397-24404.

37 G. Tai, T. Zeng, J. Yu, J. Zhou, Y. You, X. Wang, H. Wu, X. Sun, T. Hu and W. Guo, Nanoscale, 2016, 8, 2234-2241.

38 Z. Lin, B. R. Carvalho, E. Kahn, R. Lv, R. Rao, H. Terrones, M. A. Pimenta and M. Terrones, 2D Materials, 2016, 3, 022002.

39 H. Nan, Z. Wang, W. Wang, Z. Liang, Y. Lu, Q. Chen, D. He, P. Tan, F. Miao, X. Wang, J. Wang and Z. Ni, ACS Nano, 2014, 8, 5738-5745.

40 V. Madhavi, P. Kondaiah, S. S. Rayudu, O. M. Hussain and S. Uthanna, Mater. Express, 2013, 3, 135-143.

41 K. M. McCreary, A. T. Hanbicki, G. G. Jernigan, J. C. Culbertson and B. T. Jonker, Sci. Rep., 2016, 6, 19159.

42 C. Lin, X. Zhu, J. Feng, C. Wu, S. Hu, J. Peng, Y. Guo, L. Peng, J. Zhao, J. Huang, J. Yang and Y. Xie, J. Am. Chem. Soc., 2013, 135, 5144-5151.

43 D. Tonti, C. Pettenkofer and W. Jaegermann, Electrochem. Solid-State Lett., 2000, 3(5), 220-223.

44 R. Ganatra and Q. Zhang, ACS Nano, 2014, 8, 4074-4099.

45 K. F. Mak, C. Lee, J. Hone, J. Shan and T. F. Heinz, Phys. Rev. Lett., 2010, 105, 136805.

46 A. Splendiani, L. Sun, Y. Zhang, T. Li, J. Kim, C.-Y. Chim, G. Galli and F. Wang, Nano Lett., 2010, 10, 1271-1275.

47 M. A. Bissett, A. G. Hattle, A. J. Marsden, I. A. Kinloch and R. A. W. Dryfe, ACS Omega, 2017, 2, 738-745.

48 Y. Niu, S. Gonzalez-Abad, R. Frisenda, P. Marauhn, M. Drüppel, P. Gant, R. Schmidt, S. N. Taghavi, D. Barcons, J. A. Molina-Mendoza, M. S. De Vasconcellos, R. Bratschitsch, D. Perez De Lara, M. Rohlfing and A. Castellanos-Gomez, Nanomaterials, 2018, 8, 725.

49 M. Bissett, S. Worrall, I. Kinloch and R. A. W. Dryfe, Electrochim. Acta, 2016, 201, 30-37.

50 W. Zhao, Z. Ghorannevis, L. Chu, M. Toh, C. Kloc, P.-H. Tan and G. Eda, ACS Nano, 2013, 7, 791-797.

51 A. Berkdemir, H. R. Gutiérrez, A. R. Botello-Méndez, N. Perea-López, A. L. Elías, C.-I. Chia, B. Wang, V. H. Crespi, F. López-Urías, J.-C. Charlier, H. Terrones and M. Terrones, Sci. Rep., 2013, 3, 1755. 
52 G. V. Bianco, M. Losurdo, M. M. Giangregorio, A. Sacchetti, P. Prete, N. Lovergine, P. Capezzuto and G. Bruno, RSC Adv., 2015, 5, 98700-98708.

53 P. Tonndorf, R. Schmidt, P. Böttger, X. Zhang, J. Börner, A. Liebig, M. Albrecht, C. Kloc, O. Gordan, D. R. T. Zahn, S. Michaelis de Vasconcellos and R. Bratschitsch, Opt. Express, 2013, 21, 4908-4916.

54 K. Dolui and S. Sanvito, Europhys. Lett., 2016, 115, 47001.
55 M. Hirtz, A. Oikonomou, T. Georgiou, H. Fuchs and A. Vijayaraghavan, Nat. Commun., 2013, 4, 2591.

56 S. T. Wang, M. Fukuto and L. Yang, Phys. Rev. E: Stat., Nonlinear, Soft Matter Phys., 2008, 77, 031909.

57 A. Dols-Perez, L. Fumagalli and G. Gomila, Colloids Surf., B, 2014, 116, 295-302.

58 Z. V. Leonenko, E. Finot, H. Ma, T. E. S. Dahms and D. T. Cramb, Biophys. J., 2004, 86, 3783-3793.

59 L. Liang and V. Meunier, Nanoscale, 2014, 6, 5394-5401. 